Supplement of Earth Surf. Dynam., 4, 549-566, 2016

http://www.earth-surf-dynam.net/4/549/2016/

doi:10.5194/esurf-4-549-2016-supplement

(C) Author(s) 2016. CC Attribution 3.0 License.

(c) (i)

Supplement of

\title{
A reduced-complexity model for sediment transport and step-pool morphology
}

Matteo Saletti et al.

Correspondence to: Matteo Saletti (saletti@ifu.baug.ethz.ch)

The copyright of individual parts of the supplement might differ from the CC-BY 3.0 licence. 


\section{The effect of domain size in the results of CAST}

In addition to the steady-state simulations showed in the manuscript, we performed additional runs to detect the effect of domain size on the final outcome of the model. We show here results of 3 simulations having the same channel width ( $Y=20 \mathrm{~d})$ but channel length spanning 2 orders of magnitude $(X=300 \mathrm{~d}, X=3000 \mathrm{~d}$, and $X=30000 \mathrm{~d})$. All simulations reached the same equilibrium point in terms of Equilibrium Slope $\left(S_{e q}=0.12\right)$. As it can be seen in Figure $\mathrm{S} 1$, the longitudinal profiles at equilibrium look exactly the same.

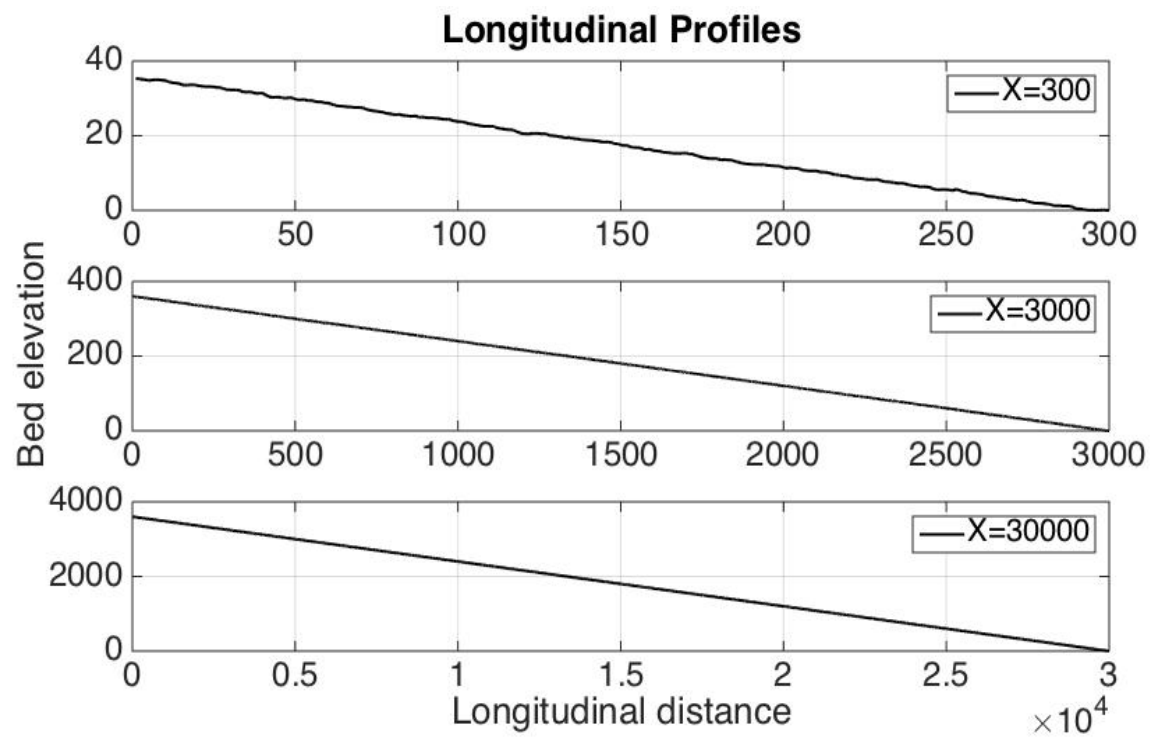

Figure S1: Longitudinal profiles at equilibrium of 3 different simulations having the same channel width $Y$ but different channel length $X$.

The domain size has of course an influence on the time needed to reach the equilibrium and on the total storage volume, as can be seen in Figure S2.

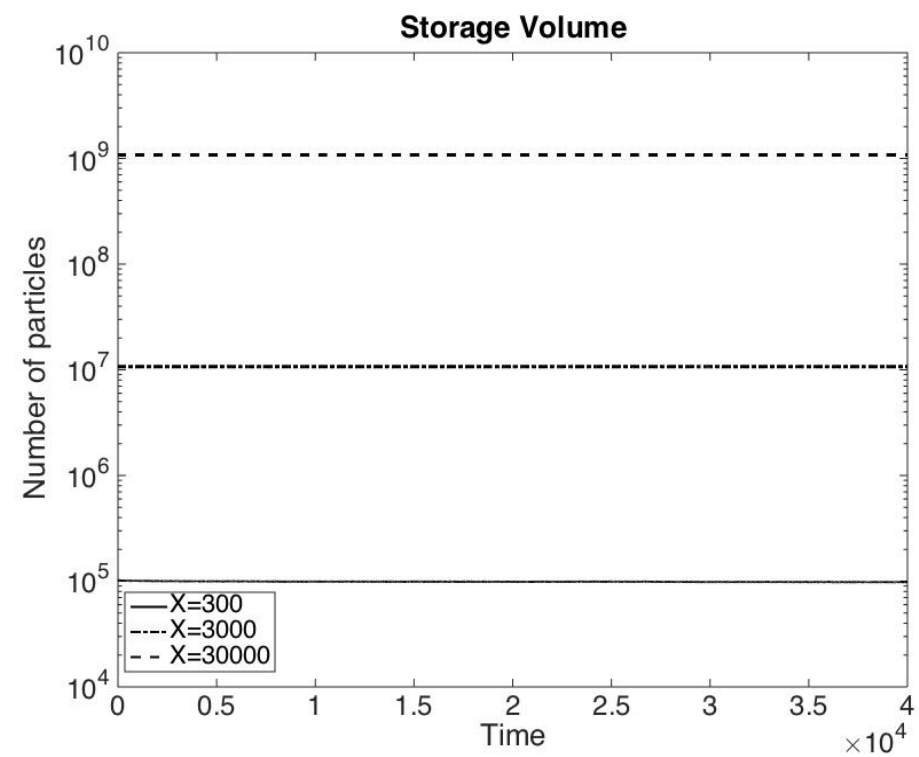

Figure S2: Time series of storage volume for simulations having different channel length $\mathrm{X}$. 